\title{
PERBEDAAN LINGKAR KEPALA PADA MANIFESTASI KRANIOFASIAL PENDERITA DOWN SYNDROME USIA 5-25 TAHUN DI UPT. SLB-E NEGERI PEMBINA SUMATERA UTARA
}

\author{
(THE DIFFERENCE OF HEAD CIRCUMFERENCE OF \\ CRANIOFACIAL MANIFESTATION IN DOWN SYNDROME \\ AT UPT. SLB-E NEGERI PEMBINA \\ OF NORTH SUMATERA)
}

Ameta Primasari, Ellin Faradina

Department of Oral Biology

Faculty of Dentistry University of Sumatera Utara

Jl. Alumni No.2 Kampus USU Medan

E-mail: ametaprima@yahoo.com

\begin{abstract}
Down syndrome is a chromosomal abnormality (trisomy 21) and the most common in live births. The most distinctive difference in Down syndrome is a craniofacial manifestation. Anthropometric measurements were carried out to see the growth of children with Down syndrome in order to determine the required treatment. The research objective was to determine the average size of craniofacial by head length, head width, face height and head circumference in patients with Down syndrome in UPT. SLB-E Negeri Pembina of North Sumatra. This research was a descriptive cross sectional study. The research sample was 23 people who had been determined based on the inclusion and exclusion criteria. Measurement was done by calculating head length, head width, face height by using a caliper and a ruler while head circumference was measured using a measuring tape. Data was analyzed using Oneway Anova test. The results showed that, there were no significant difference in head width $(\mathrm{p}=0.056)$ and face height $(\mathrm{p}=0.572)$ between the age groups. However, there were addition of the size in head length, head width, face height and head circumference in people with Down syndrome along with the increasing age. In conclusion, this study showed that there were significant differences in head length $(\mathrm{p} \leq 0.029)$ and head circumference $(\mathrm{p} \leq 0,02)$ between the age groups.
\end{abstract}

Key words: Down syndrome, craniofacial, growth and development

\begin{abstract}
Abstrak
Down syndrome merupakan abnormalitas kromosom (trisomi 21) yang paling sering terjadi dalam kelahiran hidup. Perbedaan yang paling khas adalah manifestasi kraniofasial. Pada penderitanya pengukuran antropometri dilakukan untuk melihat pertumbuhan anak Down syndrome agar dapat menyesuaikan perawatan yang diperlukan. Tujuan penelitian adalah untuk mengetahui ukuran rata-rata kraniofasial berdasarkan panjang kepala, lebar kepala, tinggi wajah dan lingkar kepala pada penderita Down syndrome di UPT. SLB-E Negeri Pembina Sumatera Utara. Jenis Penelitian adalah deskriptif dengan rancangan cross sectional study. Sampel penelitian 23 orang yang sudah ditentukan berdasarkan kriteria inklusi dan eksklusi. Pengukuran dilakukan dengan menghitung panjang kepala, lebar kepala, tinggi wajah dengan menggunakan kaliper dan penggaris sedangkan lingkar kepala diukur menggunakan pita meteran. Data dianalisis menggunakan uji Oneway Anova. Hasil penelitian menunjukkan, bahwa tidak terdapat perbedaan yang signifikan pada lebar kepala $(\mathrm{p}=0,056)$ dan tinggi wajah $(\mathrm{p}=0,572)$ antara kelompok usia. Namun demikian, ada penambahan ukuran panjang kepala, lebar kepala, tinggi wajah dan lingkar kepala pada penderita Down syndrome seiring dengan bertambahnya usia Sebagai kesimpulan, penelitian ini menunjukkan terdapat perbedaan yang signifikan pada panjang kepala $(\mathrm{p} \leq 0,029)$ dan lingkar kepala $(\mathrm{p} \leq 0,02)$ antara kelompok usia.
\end{abstract}

Kata kunci: Down syndrome, kraniofasial, tumbuh kembang 


\section{PENDAHULUAN}

Down syndrome merupakan abnormalitas kromosom (trisomi 21) yang paling sering terjadi pada kelahiran hidup. ${ }^{1}$ Di dunia kurang lebih ditemukan 8 juta anak Down syndrome. Di Indonesia ditemukan $15 \%$ dari jumlah kasus Down syndrome di dunia yaitu lebih dari 300.000 orang. Sebagai contoh salah satu daerah di Indonesia, di Serang dalam kurun waktu 4 tahun dari 2007 sampai 2010 di RSUD Serang ditemukan 2 sampai 4 kasus setiap tahunnya. ${ }^{2}$

Down syndrome adalah kelainan genetik, dimana anak yang mengalami keterbelakangan mental dan penyimpangan fisik. Jumlah kromosom 21 yang seharusnya hanya 2 , berlebih menjadi 3 buah kromosom 21 (Trisomi 21), dua kromosom didapat dari ibu (seharusnya hanya 1) dan 1 kromosom dari ayah. Kromosom yang berlebih tersebut diperkirakan terletak pada bagian lengan bawah dari kromosom 21 dan interaksinya dengan fungsi gen lainnya menghasilkan suatu perubahan homeostasis yang memungkinkan terjadinya penyimpangan perkembangan fisik dan susunan saraf pusat. $^{2}$

Salah satu perbedaan yang paling khas pada Down syndrome adalah manifestasi kraniofasial. Ditemukan penyimpangan di kedua struktur kraniofasial pada anak Down syndrome meliputi brakisefali, ukuran wajah bagian atas lebih kecil, ukuran lebar dan kedalaman mandibula kecil, secara sagital jarak mandibula ke maksila dan ke wajah bagian atas lebih pendek dan wajah bagian atas dan bagian bawah cenderung berbentuk menonjol. ${ }^{3,4,5}$

Penelitian yang dilakukan di Saudi Arabia oleh Reema mengungkapkan bahwa pada 30 penderita Down syndrome, brakisefali dijumpai lebih dari setengah kelompok Down syndrome yaitu 53,3\%. Pengamatan ini lebih rendah dari yang dilaporkan oleh Levinson dkk. yang mempelajari keragaman fitur klinis pada 50 penderita Down syndrome hingga usia 17 tahun dan menemukan bahwa $82 \%$ penderita Down syndrome mempunyai bentuk kepala brakisefali. ${ }^{3}$ Pada manusia normal umur 3-10 tahun memiliki bentuk kepala mesosefali, lalu pada usia 11-18 tahun memiliki bentuk kepala brakisefali. Pada usia 18-23 tahun bentuk kepala manusia normal menjadi hiperbrakisefali. Pada penderita Down syndrome bentuk kepala tidak berubah tetap berada di brakisefali. ${ }^{6,7}$

Antropometri adalah ilmu yang berhubungan dengan pengukuran ukuran, berat dan proporsi dari tubuh manusia. ${ }^{8}$ Antropometri dapat digunakan untuk mendapatkan nilai diagnosa yang potensial dan berfungsi dalam mengidentifikasi sebagian nilai penyimpangan dari bagian-bagian kraniofasial. ${ }^{9} \mathrm{Pe}-$ nelitian ini bertujuan untuk mengetahui hubungan antara kelainan Down syndrome terhadap penyimpangan pada struktur kraniofasial pada murid Down syndrome di UPT. SLB-E Negeri Pembina Sumatera Utara.

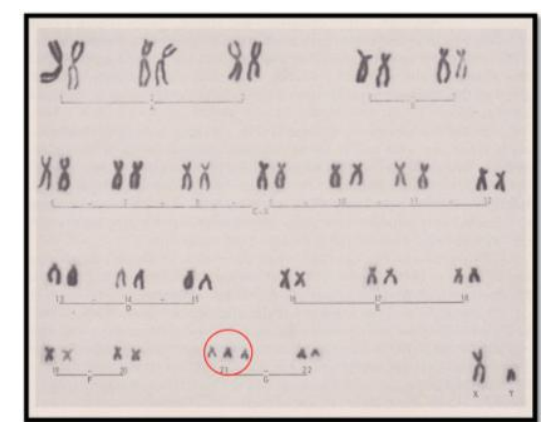

Gambar 1. Kelainan kromosom yang terjadi pada Down syndrome ${ }^{10}$

\section{BAHAN DAN METODE}

Jenis penelitian ini adalah deskriptif analitik dengan rancangan penelitian cross sectional yang dilakukan di UPT. SLB-E Negeri Pembina Sumatera Utara. Murid di Sekolah tersebut terdiri atas Down syndrome, tuna rungu, tuna grahita, tuna ganda dan autis. Pada penelitian ini juga dilakukan pengelompokan data berdasarkan jenis kelamin dan usia. Kriteria inklusi adalah anak yang didiagnosa Down syndrome di Yayasan UPT. SLB-E Negeri Pembina Sumatera Utara, bersedia untuk diperiksa dan mendapat persetujuan orang tua/guru. Kriteria eksklusi adalah anak Down syndrome yang memiliki cacat pada bagian kepala dan wajah karena kecelakaan atau terjatuh yang mengakibatkan berubahnya ukuran atau bentuk kepala dan wajah aslinya. Jumlah sampel terdiri atas 23 murid Down syndrome. Alat yang digunakan adalah kaliper, timbangan badan, pita meteran dan penggaris.

Orang tua/wali diminta mengisi lembar pengisian data selanjutnya yang memenuhi kriteria inklusi satu persatu ditimbang badan dan diukur tinggi badannya. Setelah itu sampel didudukkan di kursi dengan posisi tubuh dan kepala ditegakkan. Kemudian dilakukan pengukuran panjang kepala diukur dari glabela ke inion menggunakan kaliper (Gambar 2), setelah itu dilakukan pengukuran lebar kepala diukur dari eurion kanan ke eurion kiri menggunakan kaliper (Gambar 3), lalu dilakukan pengukuran tinggi wajah diukur dari nation ke gnation menggunakan kaliper (Gambar 4) dan terakhir dilakukan pengukuran lingkar kepala diukur dengan mengelilingi kepala tepat dibagian tulang yang paling menonjol (opistokranion) dan diatas supraorbital menggunakan pita meteran (Gambar 5). Semua hasil pengukuran dicatat pada lembar pengisian data. 
Sebelum penelitian ini dimulai, peneliti sudah mendapatkan persetujuan dari Komite Etik Penelitian Bidang Kesehatan Fakultas Kedokteran Universitas Sumatera Utara, dengan nomor: 384/KOMET/FK USU/2014 pada tanggal 29 Juli 2014.

Analisis data menggunakan uji Oneway Anova.

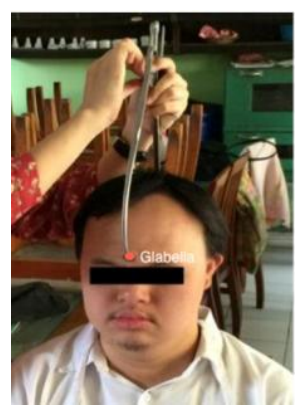

Gambar 2. Pengukuran panjang kepala

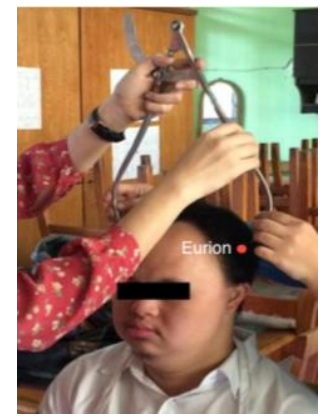

Gambar 3. Pengukuran lebar kepala

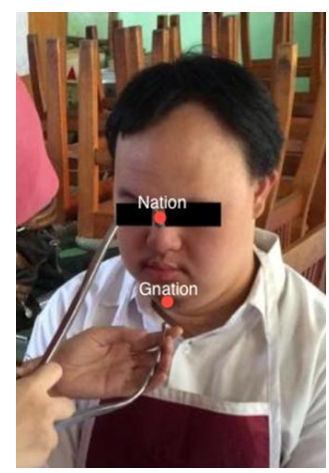

Gambar 4. Pengukuran tinggi wajah

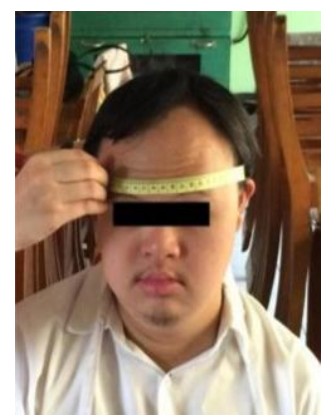

Gambar 5. Pengukuran lingkar kepala

\section{HASIL}

Pada kelompok usia 5-11 tahun persentase responden laki-laki lebih banyak daripada perempuan (26,09\% dan 17,39\%). Kelompok usia 12-16 tahun terlihat persentase responden laki-laki lebih banyak daripada perempuan $(21,74 \%$ dan $13,04 \%)$. Kelompok usia 17-25 tahun persentase responden laki-laki juga lebih banyak dari pada perempuan $(13,04 \%$ dan $8,69 \%$ ). Terjadi penambahan ukuran tinggi badan dan berat badan pada responden seiring dengan bertambahnya usia.

Tabel 1. Karakteristik Responden murid Down syndrome di Sekolah UPT. SLB-E Negeri Pembina Sumatera $\operatorname{Utara}(\mathrm{n}=23)$

\begin{tabular}{|c|c|c|c|c|}
\hline \multirow{2}{*}{$\begin{array}{c}\text { Kelompok } \\
\text { usia } \\
\text { (tahun) }\end{array}$} & \multicolumn{2}{|c|}{ Jenis kelamin } & \multirow{2}{*}{$\begin{array}{c}\text { Tinggi } \\
\text { badan } \\
(\mathrm{cm})\end{array}$} & \multirow{2}{*}{$\begin{array}{c}\text { Berat } \\
\text { badan } \\
(\mathrm{kg})\end{array}$} \\
\hline & $\begin{array}{c}\text { Laki-laki } \\
(\%)\end{array}$ & $\begin{array}{c}\text { Perempuan } \\
(\%)\end{array}$ & & \\
\hline $5-11$ & $6(26,09)$ & $4(17,39)$ & $\begin{array}{c}123,30 \pm \\
4,78\end{array}$ & $\begin{array}{c}26,05 \pm \\
5,77\end{array}$ \\
\hline $12-16$ & $5(21,74)$ & $3(13,04)$ & $\begin{array}{c}142,37 \pm \\
8,80\end{array}$ & $\begin{array}{c}40,69 \pm \\
8,14\end{array}$ \\
\hline $17-25$ & $3(13,04)$ & $2(8,69)$ & $\begin{array}{c}149,20 \pm \\
6,099\end{array}$ & $\begin{array}{c}58,80 \pm \\
20,10\end{array}$ \\
\hline
\end{tabular}

Tabel 2. Tabel rata-rata panjang kepala, lebar kepala, tinggi wajah dan lingkar kepala pada penderita Down Syndrome sesuai kelompok umur

\begin{tabular}{ccc}
\hline $\begin{array}{c}\text { Usia } \\
\text { (tahun) }\end{array}$ & $\begin{array}{c}\text { Ukuran kepala } \\
\mathrm{X} \pm \mathrm{SD}(\mathrm{cm})\end{array}$ & $\begin{array}{c}\text { Hasil uji } \\
\text { statistic }\end{array}$ \\
\hline $5-11$ & Panjang Kepala & \\
$12-16$ & $15,35 \pm 0,77$ & $\mathrm{p}=0,029 *$ \\
$17-25$ & $16,02 \pm 0,82$ & \\
\hline & $17,08 \pm 1,84$ & $\mathrm{p}=0,056$ \\
$5-11$ & Lebar Kepala & \\
$12-16$ & $13,71 \pm 0,74$ & \\
$17-25$ & $13,06 \pm 1,14$ & $\mathrm{p}=0,572$ \\
$5-11$ & $14,46 \pm 1,02$ & \\
$12-16$ & Tinggi Wajah & \\
$17-25$ & $9,13 \pm 1,26$ & \\
& $9,50 \pm 0,86$ & $\mathrm{p}=0,02 *$ \\
$5-11$ & $9,68 \pm 0,55$ & \\
$12-16$ & Lingkar Kepala & \\
$17-25$ & $49,02 \pm 1,99$ &
\end{tabular}

Uji Oneway Anova, signifikan $\mathrm{p}<0,05$

Rata-rata panjang kepala murid Down syndrome adalah $15,96 \pm 1,24 \mathrm{~cm}$. Hasil pengukuran panjang kepala yang terendah adalah kelompok usia 5-11 tahun dengan rata-rata $15,35 \pm 0,77 \mathrm{~cm}$ dan pengukuran panjang kepala yang tertinggi adalah kelompok usia 17-25 tahun dengan rata-rata 17,08 $\pm 1,84 \mathrm{~cm}$.

Terjadi perubahan ukuran panjang kepala pada kelom-pok usia 5-11 tahun terhadap kelompok usia 12-16 tahun yaitu pertambahan $0,67 \mathrm{~cm}$ dan perubahan ukuran panjang kepala pada kelompok 
usia 12-16 tahun terhadap kelompok usia 17-25 tahun dengan bertam-bah sebanyak $1,06 \mathrm{~cm}$. Pada penelitian ini ukuran panjang kepala terendah adalah pada responden laki-laki berusia 10 tahun yaitu 14,1 $\mathrm{cm}$ dan ukuran panjang kepala tertinggi pada responden perempuan berusia 18 tahun adalah 19 $\mathrm{cm}$.

Rata-rata lebar kepala murid Down syndrome adalah $13,64 \pm 1,05 \mathrm{~cm}$. Hasil pengukuran lebar kepala yang terendah adalah pada kelompok usia 1216 tahun dengan rata-rata $13,06 \pm 1,14 \mathrm{~cm}$ dan pengukuran lebar kepala yang tertinggi adalah pada kelompok usia 17-25 tahun dengan rata-rata 14,46 \pm $1,02 \mathrm{~cm}$. Terjadi perubahan ukuran lebar kepala dari kelompok usia 5-11 tahun terhadap kelompok usia 12-16 tahun yaitu pengurangan $0,65 \mathrm{~cm}$ dan perubahan ukuran lebar kepala dari kelompok usia 1216 tahun terhadap kelompok usia 17-25 tahun bertambah sebanyak $1,4 \mathrm{~cm}$. Ukuran lebar kepala terendah dimiliki oleh responden perempuan berusia 13 tahun yaitu $11,1 \mathrm{~cm}$ dan ukuran lebar kepala tertinggi dimiliki oleh responden laki-laki berusia 25 tahun yaitu $15,5 \mathrm{~cm}$.

Rata-rata tinggi wajah murid Down syndrome adalah $9,38 \pm 0,99 \mathrm{~cm}$. Hasil pengukuran tinggi wajah yang terendah adalah pada kelompok usia 5-11 tahun dengan rata-rata $9,13 \pm 1,26 \mathrm{~cm}$ dan pengukuran tinggi wajah yang tertinggi adalah kelompok usia 17-25 tahun dengan rata-rata 9,68 $\pm 0,55 \mathrm{~cm}$. Terjadi perubahan ukuran tinggi wajah dari kelompok usia 5-11 tahun dibandingkan kelompok usia 12-16 tahun dengan pertambahan yaitu $0,37 \mathrm{~cm}$ dan perubahan ukuran tinggi wajah dari kelompok usia 1216 tahun terhadap kelompok usia 17-25 tahun yang bertambah sebanyak $0,18 \mathrm{~cm}$. Ukuran tinggi wajah terendah dimiliki oleh responden perempuan berusia 9 dan 11 tahun yaitu 7,5 cm dan ukuran tinggi wajah tertinggi dimiliki oleh responden laki-laki berusia 10 tahun yaitu $11,1 \mathrm{~cm}$.

Rata-rata lingkar kepala murid Down syndrome adalah $51,02 \pm 2,70 \mathrm{~cm}$. Hasil pengukuran yang terendah adalah kelompok usia 5-11 tahun dengan rata-rata 49,02 $\pm 1,99 \mathrm{~cm}$ dan pengukuran lingkar kepala yang tertinggi adalah kelompok usia 17-25 tahun dengan rata-rata $53,36 \pm 2,66 \mathrm{~cm}$. Terjadi perubahan ukuran lingkar kepala pada kelompok usia 5-11 tahun terhadap kelompok usia 12-16 tahun yaitu $3,04 \mathrm{~cm}$ dan perubahan ukuran lingkar kepala dari kelompok usia 12-16 tahun terhadap kelompok usia 17-25 tahun adalah $1,30 \mathrm{~cm}$. Ukuran lingkar kepala terendah dimiliki oleh responden perempuan berusia 11 tahun yaitu 46,3 cm dan ukuran lingkar kepala tertinggi dimiliki oleh responden laki-laki berusia 25 tahun yaitu $56,8 \mathrm{~cm}$.
Terlihat terjadinya penambahan ukuran panjang kepala dari kelompok usia 5-11 tahun ke 12-16 tahun lalu ke 17-25 tahun pada penderita Down syndrome.

\section{Lingkar Kepala}

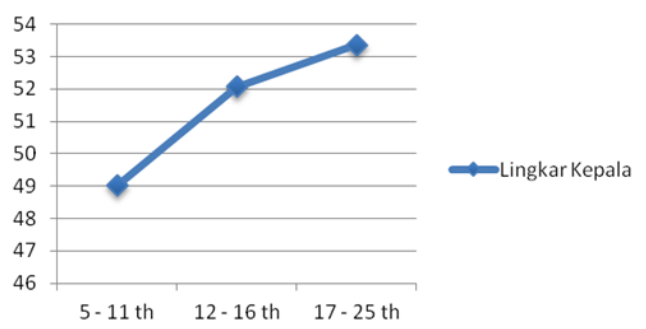

Grafik 1. Kepala Penderita Down Syndrome usia 5-11 tahun ke 12-16 tahun lalu ke 17-25 tahun

Pada Grafik 1 dapat dilihat terjadinya penambahan ukuran lingkar kepala dari kelompok usia 5-11 tahun ke 12-16 tahun lalu ke 17-25 tahun pada penderita Down syndrome.

\section{PEMBAHASAN}

Pertumbuhan yang paling besar terjadi pada lingkar kepala pada kelompok usia 12-16 tahun. Namun demikian terjadi perubahan ukuran lebar kepala bahkan terjadi pengurangan pada kelompok usia 12-16 tahun. Hal ini disebabkan karena pengaruh Down syndrome yang mengakibatkan terganggunya pertumbuhan dan juga akibat variasi individu, yang tiap individu memiliki pola pertumbuhan yang berbedabeda disebabkan faktor tertentu. ${ }^{11,12}$

Hasil penelitian panjang kepala menunjukkan terdapat perbedaan pada ukuran panjang kepala pada anak Down syndrome dan anak normal. Rata-rata panjang kepala anak Down syndrome usia 12-16 tahun adalah 16,02 $\pm 0,82 \mathrm{~cm}$. Hasil ini lebih kecil dibandingkan penelitian oleh Nuraini dkk. pada murid normal usia 12-18 tahun di Surabaya yaitu 16,80 cm. ${ }^{11}$ Terdapat perbedaan sebesar $0,78 \mathrm{~cm}$ pada ukuran panjang kepala anak Down syndrome dan anak normal. Hal ini mungkin disebabkan karena abnormalitas perkembangan kromosom anak Down syndrome pada masa embrio sehingga menyebabkan gangguan kematangan, pembelahan dan pertumbuhan sel-sel tubuh serta gangguan perkembangan otak. ${ }^{11}$

Ukuran panjang kepala dipengaruhi oleh tinggi badan dan berat badan. Pada penelitian yang dilakukan oleh Anibor dkk. di Nigeria memperlihatkan bahwa tinggi badan mempengaruhi ukuran panjang kepala. Hasil penelitian tersebut menunjukkan bahwa panjang kepala mengikuti tinggi badan secara konstan. ${ }^{12}$ Pada penelitian yang dilakukan Bayat di Iran melaporkan bahwa berat badan juga mempengaruhi 
ukuran panjang kepala. Penelitian Bayat dkk. yang dilakukan pada murid usia 18-26 tahun dengan mengukur tinggi badan, berat badan, panjang kepala, lebar kepala dan lingkar kepala. ${ }^{13}$ Hasil penelitian menunjukkan korelasi positif antara volume otak dan pengukuran antropometri termasuk tinggi, berat, usia dan indeks massa tubuh. Korelasi tertinggi ditemukan pada volume otak dan indeks massa tubuh. Peningkatan volume tengkorak juga dihubungkan dengan peningkatan pada tinggi, berat dan indeks massa tubuh. Pengukuran tubuh digunakan untuk menghitung indeks massa tubuh dan juga pengukuran kepala seperti panjang, lebar dan lingkar kepala dapat digunakan untuk mengukur tengkorak kepala. Perhitungan ukuran tengkorak dan ukuran otak ditemukan bahwa tinggi badan dan berat badan mempengaruhi ukuran pada tengkorak kepala. ${ }^{14}$

Hasil penelitian lebar kepala menunjukkan terdapat perbedaan pada ukuran lebar kepala pada anak Down syndrome dan anak normal. Rata-rata lebar kepala anak Down syndrome usia 12-16 tahun adalah 13,06 $\pm 1,14 \mathrm{~cm}$. Hasil ini lebih kecil dibandingkan penelitian oleh Nuraini Nunik dkk. pada murid normal usia 12-18 tahun di Surabaya yaitu $13,90 \mathrm{~cm} .{ }^{11}$ Terdapat perbedaan sebesar $0,84 \mathrm{~cm}$ pada ukuran lebar kepala anak Down syndrome dan anak normal. Hal ini mungkin disebabkan karena adanya gangguan growth hormone $(\mathrm{GH})$ pada anak Down syndrome, karena growth hormone berfungsi untuk mengendalikan pertumbuhan sel tubuh termasuk pertumbuhan tulang dan massa otot rangka. ${ }^{11}$ Adanya penurunan ukuran lebar kepala pada kelompok usia 5-11 tahun dan kelompok usia 12-16 tahun pada penderita Down syndrome, hal ini dapat dikarenakan terdapat beberapa karakterisitik variasi pada penderita Down syndrome. Variasi ini dipengaruhi oleh faktor genetik dari ekstra kromosom 21 dan faktor yang diturunkan dari orang tua.

Pertumbuhan tulang, termasuk kranium yang menentukan ukuran kepala individu terjadi lewat aposisi pada periosteum. Pada penderita Down syndrome, sinus spenoidalis dan sinus frontalis tidak berkembang sehingga dapat mempengaruhi bentuk kepala dan wajah. ${ }^{11}$ Pe-nurunan ukuran juga terjadi dikarenakan perbedaan hasil yang didapat dari individu yang berbeda, di-mana tiap individu memiliki pola pertumbuhan yang berbeda-beda pula. Hal ini kemungkinan disebabkan oleh beberapa faktor diantaranya genetik dan lingkungan seperti nutrisi, penyakit dan lain sebagainya. Sampai dengan dewasa, interaksi antara faktor genetik dan lingkungan mengikuti dan mengontrol proses pertumbuhan dan perkembangan dan menen- tukan morfologi dan sifat-sifat fisiologis masingmasing individu. ${ }^{12}$

Hasil penelitian tinggi wajah menunjukkan terdapat perbedaan pada ukuran tinggi wajah pada anak Down syndrome dan anak normal. Rata-rata tinggi wajah anak Down syndrome usia 12-16 tahun adalah $9,50 \pm 0,86 \mathrm{~cm}$. Hasil ini lebih kecil dibandingkan penelitian oleh Nuraini dkk. pada murid normal usia 12-18 tahun di Surabaya yaitu $13,00 \mathrm{~cm} .{ }^{11}$ Terdapat perbedaan sebesar $3,5 \mathrm{~cm}$ pada ukuran tinggi wajah anak Down syndrome dan anak normal. Hal ini mungkin disebabkan karena anak Down syndrome mempunyai ukuran tinggi hidung yang pendek dan juga diketahui pada anak Down syndrome mengalami dismorfologi kraniofasial, termasuk pada ukuran mandibula yang kecil. Ukuran mandibula yang kecil pada Down syndrome disebabkan karena perpindahan dan penyebaran kerusakan pada sel-sel puncak saraf mandibula saat pembentukan embrio, sehingga mandibula tidak dapat terbentuk dengan baik. Kedua hal ini diperkirakan menyebabkan tinggi wajah pada anak Down syndrome menjadi lebih rendah daripada anak normal. ${ }^{15}$

Hasil penelitian lingkar kepala menunjukkan terdapat perbedaan pada ukuran lingkar kepala pada anak Down syndrome dan anak normal. Rata-rata lingkar kepala anak Down syndrome usia 12-16 tahun adalah 52,06 $\pm 1,72 \mathrm{~cm}$. Hasil ini lebih kecil dibandingkan penelitian oleh Gabriel dkk. pada murid normal usia 3-18 tahun di Nigeria yaitu 52.42. ${ }^{16}$ Terdapat perbedaan sebesar $0,36 \mathrm{~cm}$ pada ukuran lingkar kepala anak Down syndrome dan anak normal. Hal ini mungkin disebabkan karena kelainan genetik mengganggu pertumbuhan korteks serebral bayi selama bulan-bulan awal perkembangan janin sehingga menyebabkan ukuran kepala menjadi kecil atau disebut juga mikrosepali. Bayi yang lahir dengan mikrosepali akan memiliki kepala lebih kecil daripada kepala anak normal. ${ }^{17}$

Ukuran lingkar ke-pala dipengaruhi oleh tinggi badan dan berat badan. Pada penelitian yang dilakukan di Nigeria menunjukkan bahwa tinggi badan mempengaruhi ukuran lingkar kepala. Hasil penelitian tersebut terlihat bahwa ukuran lingkar kepala menurun seiring dengan meningkatnya ukuran tinggi badan. ${ }^{13}$ Pada penelitian yang dilakukan Geraedts dkk. adanya korelasi antara lingkar kepala terhadap berat badan dan tinggi badan. ${ }^{18}$ Penelitian menunjukkan bahwa korelasi antara lingkar kepala dan berat badan lebih besar dari pada korelasi antara lingkar kepala dan tinggi badan. Korelasi tertinggi antara lingkar kepala dan berat badan terjadi pada saat lahir. Korelasi antara lingkar kepala dan berat badan menurun dengan cepat lalu ke tingkat yang stabil dan berhenti pada puncak remaja. ${ }^{18}$ 
Indeks sefalik horizontal terbagi atas dolikosefali $(<74,9)$, mesosefali $(75-79,9)$, brakisefali $(80-84,9)$ dan hiperbrakisefali $(<85)$. Nilai indeks sefalik horizontal didapatkan dengan rumus:

$$
\text { Indeks sefalik horizontal }=\frac{\text { Lebar kepala }}{\text { Panjang kepala }} \times 100
$$

Hasil penelitian ini pada penderita Down syndrome usia 17-25 tahun adalah 84,66 dan masuk dalam kategori brakisefali $(80-84,9)$. Berdasarkan penelitian Gujaria dkk. pertumbuhan normal usia 1723 tahun memiliki bentuk kepala hiperbrakisefali $(>85)^{7}$

\section{DAFTAR PUSTAKA}

1. Rahmawati A. Hubungan antara usia ibu hamil dengan resiko terjadinya kelahiran sindroma down. Jurnal Kesetaraan dan Keadilan Gender 2011; 6: 155-64.

2. Laksono S, Qomariyah, Purwaningih E. Persentase distribusi penyakit genetik dan penyakit yang dapat disebabkan oleh faktor genetik di RSUD Serang. Majalah Kesehatan PharmaMedika 2011. Jun 2: 155-61.

3. Al-Shawaf R, Al-Faleh W. Craniofacial characteristic in Saudi down's syndrome. J Dent Sciences 2011; 2: 17-22.

4. Moraes MEL, Moraes LC, Dotto GN, Dotto PP, Santos LRA. Dental anomalies in patients with down syndrome. Braz Dent J 2007; 18(4): 346-50.

5. Al-Hussuna A. Statistical variation of three dimensional face models. Tesis. Copenhagen: Multimedia Technologies Master Thesis Project IT- University of Copenhagen, 2003: 33.

6. Ligha AE, Fawehinmi HB. Canthal and cephalic indexes of Nigeria children. Aust. J. Basic \& Appl. Sci 2011; 5: 3019 .

7. Gujaria IJ, Salve VM. Comparison of cephalic index of three states of india. Int J Pharm Bio Sci 2012; 3: 1025.

8. Kurnia C, Susiana, Husin W. Facial indices in Chinese etnic students aged 20-22. J Dent In 2012; 19: 1-4.

9. Bagic I, Verzak Z. Craniofacial anthropometric analysis in down's syndrome patients. Coll. Antropol. 2003; 27 Suppl 2: 23-30.
Dapat disimpulkan bahwa terdapat perbedaan yang signifikan pada panjang kepala dan lingkar kepala antar kelompok usia. Sementara itu tidak terdapat perbedaan yang signifikan pada lebar kepala dan tinggi wajah antar kelompok usia. Perlu penelitian selanjutnya mengenai efek tumbuh kembangnya kraniofasial pada Down syndrome terhadap keadaan gigi geligi dan kesehatan rongga mulut.

10. Yashwanth R, Chandra N, Gopinath PM. Chromosomal abnormalities among children with congenital malformations. Int J Hum Genet 2010; 10: 59.

11. Nuraini N, Chusida A, Soegeng B. Perbandingan tinggi, panjang dan lebar kepala antara penderita sindroma down dan anak normal usia 12-18 tahun. Oral Biology Dent J 2011; 3: 27-9.

12. Anibor E, Eboh D, Etetafia M. A study of craniofacial parameters and total body height. Adv. Appl. Sci. Res., 2011; 2: 400-05.

13. Bayat PD, Ghanbari A, Sohouli P. Correlation of skull size and brain volume, with age, weight, height dan body mass index of arak medical sciences students. Int. J. Morphol 2012; 30: 158-59

14. Reddy YM, Sreekanth CAB, Reddy BV, Kumar LB. The effect of genetic and environmental factors on craniofacial complex: A twin study. The journal of Indian Orthodontic Society 2011; 45: 109.

15. Wiseman F, Alford K, Tybulewicz V, Fisher E. Down Syndrome-recent progress and future prospects. Human Molecular Genetics 2009; 18: 77.

16. Gabriel O, Leyira Y, Peter O. Measurements of head circumference, interchantal distances, chantal index and circumference interorbital index of ikwerre school children in Nigeria. Journal of Natural Sciences Research 2013; 3: 16.

17. Davis CP. Microcephaly. <http://www.medicinet. com/microcephaly/page2.htmllwhat-causes-microcephaly> (1 Oktober 2014).

18. Geraedts E, Dommelen P, Caliebe J. Association between head circumference and body size. Horm Res Paediatr 2011; 75: 213-19. 